\title{
ELECTRICAL AND THERMAL PROPERTIES OF $\mathrm{Na}_{1-\mathrm{x}} \mathrm{Li}_{\mathrm{x}} \mathrm{NbO}_{3}(\mathrm{x}=0.08,0.1$ AND 0.2) CERAMICS NEAR THE MORPHOTROPIC PHASE BOUNDARY REGION
}

\begin{abstract}
$\mathrm{Na}_{1-\mathrm{x}} \mathrm{Li}_{\mathrm{x}} \mathrm{NbO}_{3}$ ceramics (for $\mathrm{x}=0.08,0.1,0.2$ ) were fabricated by the conventional solid state reaction method. The influence of $\mathrm{LiNbO}_{3}$ on the microstructure, electric, thermal properties of $\mathrm{Na}_{1-\mathrm{x}} \mathrm{Li}_{\mathrm{x}} \mathrm{NbO}_{3}$ ceramics was studied and a significant influence of doped $\mathrm{Li}$ ions on the electrical properties was observed. The electrical properties were improved and are described as the best for $\mathrm{x}=0.1$ (near a morphotropic phase boundary) $\mathrm{Na}_{1-\mathrm{x}} \mathrm{Li}_{\mathrm{x}} \mathrm{NbO}_{3}$ solid solutions. After crossing the morphotropic phase boundary for $\mathrm{x}=0.2$, the electric properties are getting worse. These types of solid compounds show some interesting properties suitable for practical applications.
\end{abstract}

Keywords: perovskite, morphotropic phase boundary, electric properties, DSC

\section{Introduction}

The perovskite $\mathrm{ABO}_{3}$ compounds and their solid solutions are interesting for technological applications. These solid solutions, with a composition close to the so-called morphotropic phase boundaries (MPB), usually have excellent dielectric, ferroelectric and piezoelectric properties [1]. $\mathrm{NaNbO}_{3}-\mathrm{LiNbO}_{3}$ (hereafter referred to as NLN) solid solutions are promising materials from the point of view of both fundamental research and applications.

$\mathrm{NaNbO}_{3}(\mathrm{NN})$ shows six structural phase transitions [2]; five of them occur in the high temperature range. In all of these transitions, tilting of the oxygen octahedrons in the structure can be observed [2]. Similar behavior can be observed in other compounds e.g. double sulfates $[3,4]$. The phase transition, at temperature $360^{\circ} \mathrm{C}$, from antiferroelectric phase with orthorhombic structure (Pbma) to the antiferroelectric orthorhombic structure (Pnmm) is accompanied by the maximum change of dielectric permittivity [2,5-7].

$\mathrm{LiNbO}_{3}(\mathrm{LN})$ is a ferroelectric of ilmenite structure. LN undergoes a second order phase transition from the ferroelectric phase to paraelectric phase with a Curie temperature of about $1200^{\circ} \mathrm{C}$ [8]. The lead-free perovskite single-crystalline and polycrystalline NLN have been extensively examined using different methods [8-15]. There are two MPB in the NLN system - one at low $\mathrm{LN}$ content and the other at $\mathrm{x}=0.11-0.125$. The second MPB has the most prospective applications [16]. The effect of $\mathrm{Li}$ concentration on the structural, dielectric and pyroelectric properties of $\mathrm{Na}_{1-\mathrm{x}} \mathrm{Li}_{\mathrm{x}} \mathrm{NbO}_{3}$ solid solutions for $(\mathrm{x}=0-0.06)$ was presented in publication [17]. The studies have shown that the dielectric and pyroelectric behavior of $\mathrm{Na}_{1-\mathrm{x}} \mathrm{Li}_{\mathrm{x}} \mathrm{NbO}_{3}$ ceramics depends strongly on the $\mathrm{Li}$ concentration. The presence of $\mathrm{Li}$ ions influences the phase transition point, thermal hysteresis, the permittivity characteristic and remnant polarization. The influence of uniaxial pressure on the electrical properties of NLN $(x=0.08,0.1,0.2)$ ceramics were presented in the article [18]. Investigation of the dielectric properties shows that the uniaxial pressure strongly affects the maximum of the permittivity, whereas the permittivity peak changes shape to the most flattened curve and is shifted to lower temperatures.

The present work aims to study the influence of LN concentration on the electric properties of $\mathrm{Na}_{1-\mathrm{x}} \mathrm{Li}_{\mathrm{x}} \mathrm{NbO}_{3}$ (NLN) solid solutions for $(\mathrm{x}=0.08,0.1,0.2)$.

\section{Experimental procedure}

NLN ceramics $(x=0.08,0.1,0.2)$ were synthesized by conventional technology $[1,19]$ :

$$
\begin{aligned}
& \left(\frac{1-x}{2}\right) \mathrm{Na}_{2} \mathrm{CO}_{3}+\left(\frac{x}{2}\right) \mathrm{Li}_{2} \mathrm{CO}_{3}+ \\
& +\left(\frac{1}{2}\right) \mathrm{Nb}_{2} \mathrm{O}_{5} \rightarrow \mathrm{Na}_{1-\mathrm{x}} \mathrm{Li}_{\mathrm{x}} \mathrm{NbO}_{3}+\frac{1}{2} \mathrm{CO}_{2}
\end{aligned}
$$

The samples were preparated in a 2-step sintering process with conditions: $900^{\circ} \mathrm{C}$ for 4 hours and $1130^{\circ} \mathrm{C}$ for 3 hours. Samples were obtained with a density of $95 \%$ of the theoretical density. According to X-ray spectroscopy, the ceramics showed single-phase orthorhombic perovskite-type structure for $\mathrm{x}<0.15$ [20]. The ceramics with $x=0.20$ showed coexisting orthorhom-

\footnotetext{
INSTITUTE OF TECHNOLOGY, PEDAGOGICAL UNIVERSITY, UL. PODCHORĄŻYCH 2, 30-084 KRAKÓW, POLAND

Corresponding author: kkoniec@up.krakow.pl
} 
bic and rhombohedral phases [21]. Such coexistence may be a fingerprint of decomposition of the solid solution. Homogeneous samples with $x>0.15$ can be obtained only using special techniques, e.g. quenching. On slow cooling, the ceramics decompose gradually to give NLN solid solutions with smaller $x$ values, mixed with minor quantities of $\mathrm{LiNbO}_{3}$ (or $\mathrm{LiNbO}_{3}-$ based solid solutions) [22].

A Hitachi S-4700 scanning electron microscope (SEM), was used for the investigation of the microstructure.

The specific heat measurements were carried out using a Netzsch DSC F3 Maia scanning calorimeter in the temperature range from $-150^{\circ} \mathrm{C}$ to $550^{\circ} \mathrm{C}$ under an argon atmosphere at a flow rate of $30 \mathrm{ml} / \mathrm{min}$. The specimen consisted of single piece of crystal of average mass $25 \mathrm{mg}$ which was placed in an alumina crucible. The data were collected upon heating and cooling with a constant rate of $10^{\circ} \mathrm{C} / \mathrm{min}$.
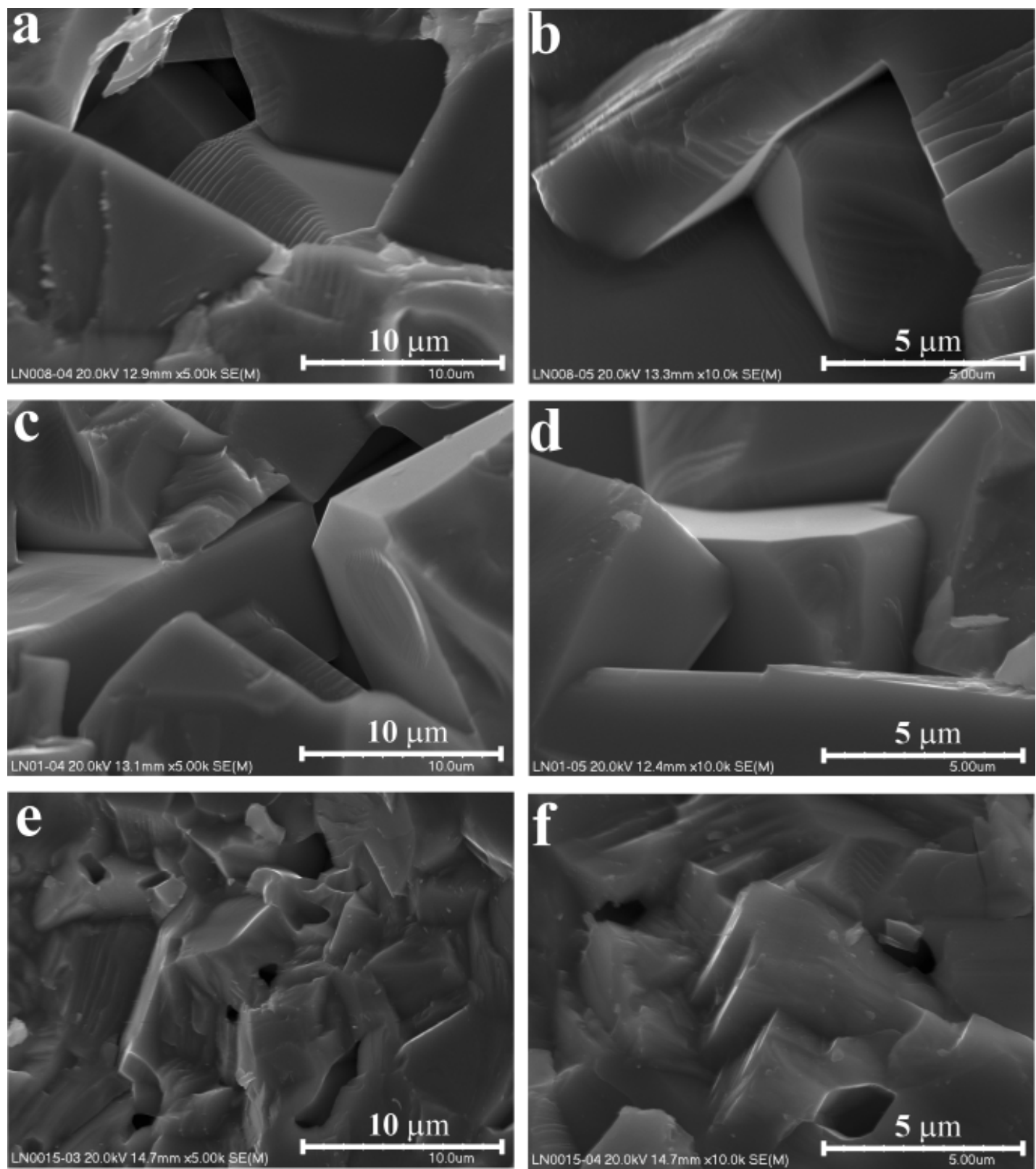

Fig. 1. SEM micrograph of $\mathrm{Na}_{1-\mathrm{x}} \mathrm{Li}_{\mathrm{x}} \mathrm{NbO}_{3}$ ceramic for $\mathrm{x}=0.08(\mathrm{a}-\mathrm{b}), \mathrm{x}=0.1$ (c-d), $\mathrm{x}=0.2$ (e-f). Where: Fig 1a, $1 \mathrm{c}, 1 \mathrm{e}$ is $\times 5000$ magnification and Fig $1 \mathrm{~b}, 1 \mathrm{~d}, 1 \mathrm{f}$ is $\times 10000$ magnification
The dielectric measurements were performed using a Gwinstek Precision LCR Meter series LCR 8110G in temperature range $20 \div 600^{\circ} \mathrm{C}$ at a constant rate of temperature change of $4^{\circ} \mathrm{C} / \mathrm{min}$ and in the frequency range $100 \mathrm{~Hz}$ to $2 \mathrm{MHz}$. The samples were previously electroded with a silver paste. Prior to the measurements, the samples were heated to $600^{\circ} \mathrm{C}$ and kept at this temperature for 60 minutes.

\section{Results and discussion}

The Fig. 1 presents the SEM micrograph of NLN ceramics for $\mathrm{x}=0.08(\mathrm{a}-\mathrm{b}), \mathrm{x}=0.1(\mathrm{c}-\mathrm{d})$ and $\mathrm{x}=0.2(\mathrm{e}-\mathrm{f})$. For the sample containing 0.08 and $0.1 \mathrm{LN}$, the grains had regular shapes and were well developed. Further increasing the LN content to 0.2 gives rise to some abnormal grains and porous, layered struc- 

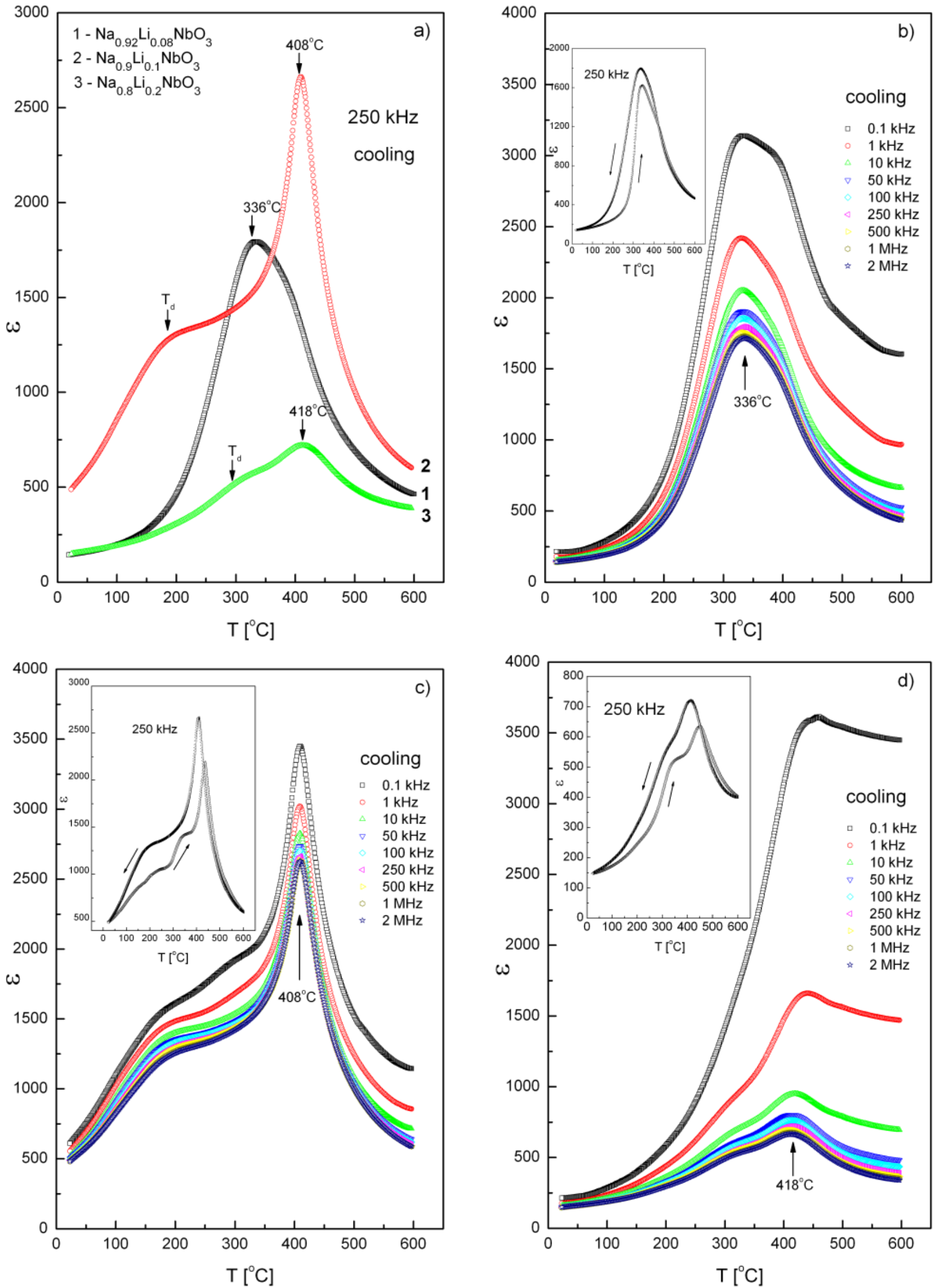

Fig. 2. Temperature dependences of electric permittivity of $\mathrm{Na}_{1-\mathrm{x}} \mathrm{Li}_{\mathrm{x}} \mathrm{NbO}_{3}$ for $\mathrm{x}=0.08-0.2$, frequency $\mathrm{f}=250 \mathrm{kHz}$ (a) and temperature/frequency evolution of the electric permittivity $\varepsilon$ of $\mathrm{Na}_{1-\mathrm{x}} \mathrm{Li}_{\mathrm{x}} \mathrm{NbO}_{3}$ for $\mathrm{x}=0.08$ (b), $\mathrm{x}=0.1$ (c), $\mathrm{x}=0.2$ (d). The inserts shows the temperature evolution of $\varepsilon$ on heating/cooling, frequency $\mathrm{f}=250 \mathrm{kHz}$ 

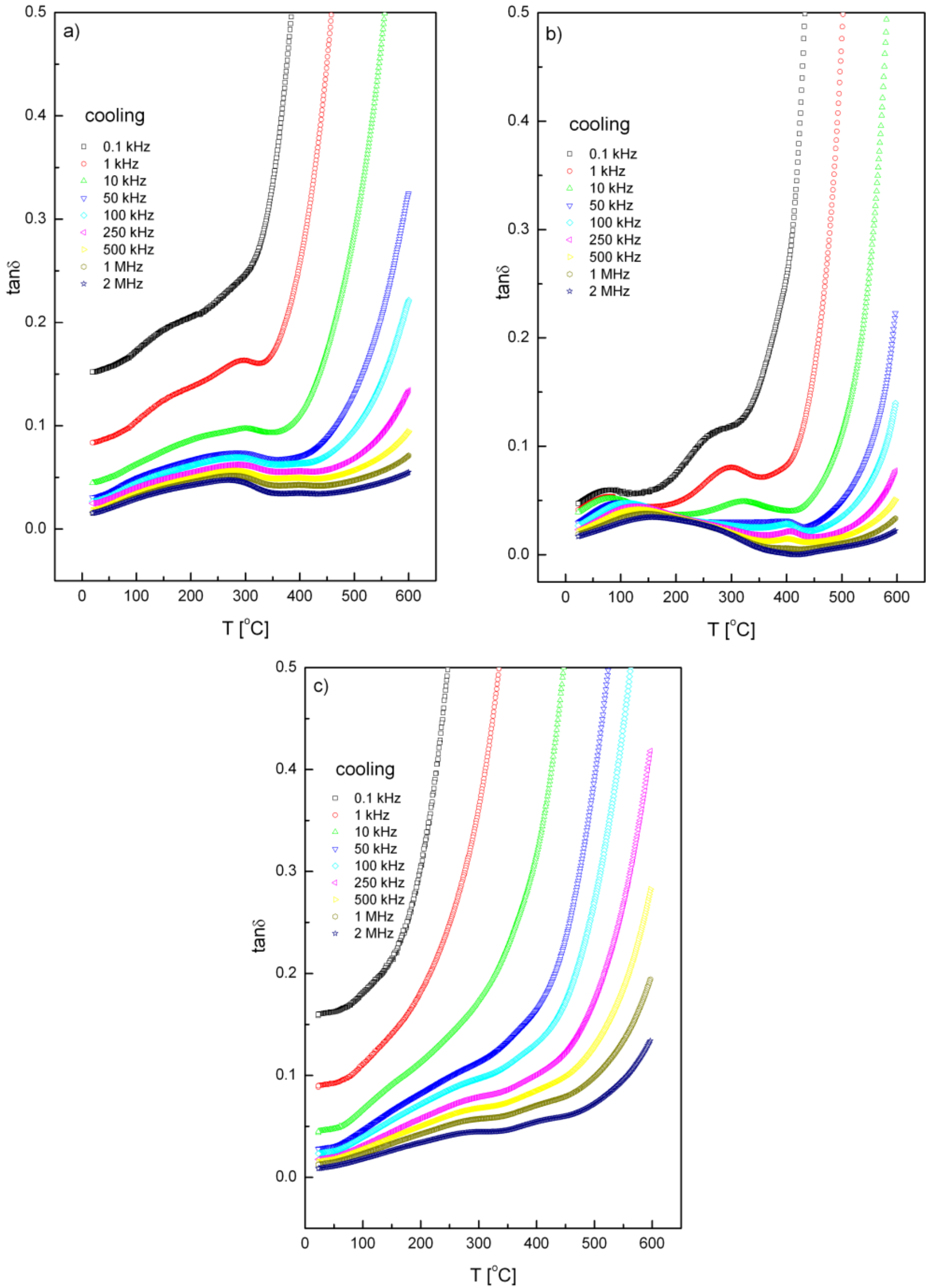

Fig. 3. Temperature dependences of the dielectric losses of $\mathrm{Na}_{1-\mathrm{x}} \mathrm{Li}_{\mathrm{x}} \mathrm{NbO}_{3}$ ceramics for $\mathrm{x}=0.08(\mathrm{a}), \mathrm{x}=0.1$ (b), $\mathrm{x}=0.2$ (c) 
tures - the plates observed in the ceramics are randomly oriented. More complex grain structures with some amount of pores and with less well visualized grain boundaries are visible in Fig. 1e and 1f. Probably the sintering temperature of samples with this content of Li is too high. Some signs of liquid phase in the SEM micrographs may confirm this conclusion.

Fig. 2a presents an example of the temperature evolution of the electric permittivity $(\varepsilon)$ of NLN for $\mathrm{x}=(0.08,0.1,0.2)$ for frequency $\mathrm{f}=250 \mathrm{kHz}$ (electric field measurements). The main maximum $\left(\mathrm{T}_{\mathrm{m}}\right)$ of electric permittivity is observed at about $\mathrm{T}_{\mathrm{m}}=336^{\circ} \mathrm{C}, 408^{\circ} \mathrm{C}, 418^{\circ} \mathrm{C}$ for $\mathrm{x}=0.08,0.1,0.2$ respectively. Comparing the results with temperatures given in the literatures, we have observed some differences in the values. They are probably due to differences in preparation of the materials $[1,23]$. The maximum of permittivity values $\left(\varepsilon_{\mathrm{m}}\right)$ are $\varepsilon_{\mathrm{m}}=1800,2700$ and 750 for $\mathrm{x}=0.08,0.1$ and 0.2 respectively. These measurements have shown that content of $\mathrm{LN}$ for $\mathrm{x}=0.08 \div 0.2$ has a strong impact on the temperature of the main phase transition $\left(336^{\circ} \mathrm{C} \div 418^{\circ} \mathrm{C}\right)$, the value of electric permittivity, the frequency dispersion and the ferroelectric properties. The reason for this behavior may be the fact that, in ferroelectrics with substitutional impurities (mixed ferroelectrics), at high temperatures polar regions can form in the surroundings of these impurities [24]. Following the research conducted in this work, we claim that the maximum of dielectric permittivity doesn't depend on the frequency of the measuring field (see paper [1]), but we observed additional local maxima $\left(\mathrm{T}_{\mathrm{d}}\right.$ ) at about $\mathrm{T}_{\mathrm{d}}=190^{\circ} \mathrm{C}$ (distinct) and $290^{\circ} \mathrm{C}$ (weak) for $\mathrm{x}=0.1$ and 0.2 , respectively. These anomalies can be connected with the formation of another phase.

Fig. 2b, c, d presents the temperature/frequency evolution of the electric permittivity $(\varepsilon)$ of NLNfor $\mathrm{x}=(0.08,0.1,0.2)$. The pronounced frequency dispersion is observed for all the lithium content. The paper [1] does not report the frequency and thermal dispersion.Very high frequency dispersion is visible above the Curie temperature (perticularly for $\mathrm{x}=0.08$ and 0.2 ). The local deformation accompanied by the substitution of Li- by Na- ions can lead to the formation of local dipoles (polar regions) in our materials. These polar regions are probably nuclei of low-temperature weak ferroelectricity. The reorientation of these regions in an external electric field could explain the observed electric dispersion (Fig. 2 b-d). Inserts in figures $2 b-$ $2 \mathrm{~d}$ show examples of thermal hysteresis for frequency $250 \mathrm{kHz}$. Significant thermal hysteresis $\left(\Delta \mathrm{T}_{\mathrm{m}}=\mathrm{T}_{\text {mheating }}-\mathrm{T}_{\text {mcooling }}\right.$ and $\Delta \varepsilon=\varepsilon_{\text {cooling }}-\varepsilon_{\text {heating }}$ ) occurs for temperatures lower than Curie temperature. When the sample is heated and cooled the values described by this hysteresis are: $\left(\Delta \mathrm{T}_{\mathrm{m}} \approx 10^{\circ} \mathrm{C}, \Delta \varepsilon \approx 200\right) ;\left(\Delta \mathrm{T}_{\mathrm{m}} \approx\right.$ $\left.30^{\circ} \mathrm{C}, \Delta \varepsilon \approx 500\right) ;\left(\Delta \mathrm{T}_{\mathrm{m}} \approx 40^{\circ} \mathrm{C}, \Delta \varepsilon \approx 100\right)$ for $\mathrm{x}=0.08,0.1$, 0.2 respectively. These values suggest that a first order phase transition occurs.

Fig. 3a, b, c show the temperature dependence of the dielec$\operatorname{tric}$ loss $\tan \delta$.We are seeing a decrease of $\tan \delta$ with increasing frequency for all investigated composition. A clear anomaly can be observed for $\mathrm{x}=0.08$ and 0.1 in the range of the phase transition. For lithium content $x=0.2$ a significant diffusion dispersion of the observed anomalies is seen. Such behavior suggests a significant increase of the electrical conductivity in the material already in the ferroelectric phase.

Further evidence of phase transitions was obtained by DSC study Fig. 4. Dependence of the heat flow shows distinct peaks at $330^{\circ} \mathrm{C}, 380^{\circ} \mathrm{C}, 390^{\circ} \mathrm{C}$. These temperatures correspond to the temperature $\mathrm{T}_{\mathrm{m}}$.

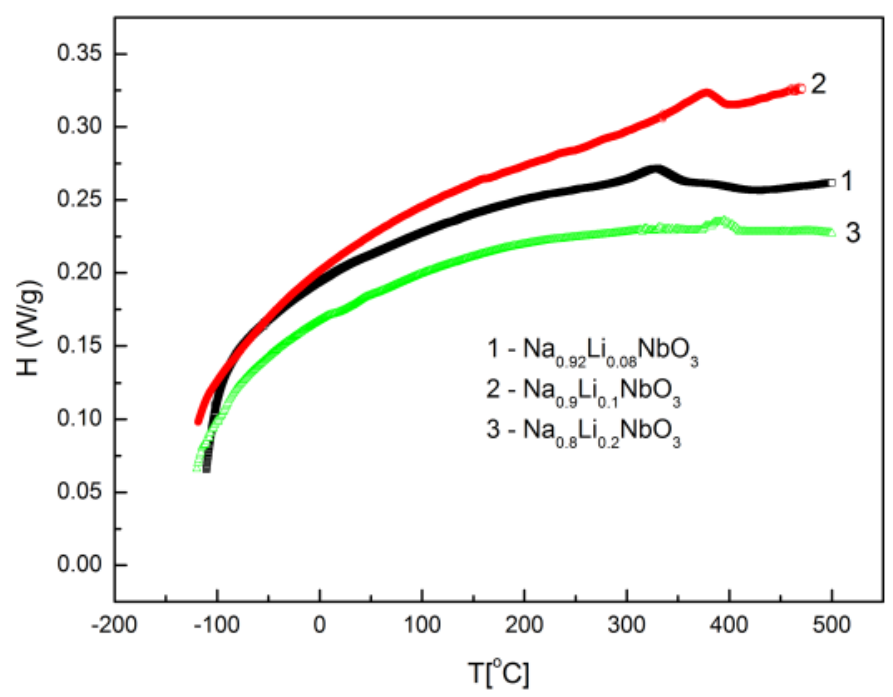

Fig. 4. Temperature evolution of the heat flow of $\mathrm{Na}_{1-\mathrm{x}} \mathrm{Li}_{\mathrm{x}} \mathrm{NbO}_{3}$ ceramics

\section{Conclusions}

NLN ceramics with a density of $95 \%$ (of theoretical density) were processed by the conventional method. Microstructural, electrical, thermal measurements were carried out. The microstructural measurements show that for content $\mathrm{x}=0.2$ abnormal grains and porosity are observed. The electrical measurements revealed the strong impact of phase transitions on the value of electric permittivity, the frequency dispersion and temperatures. Such behavior in these materials is caused by substitutional impurities (mixed ferroelectrics). The impurities cause the creation of polar regions, which are probably nuclei of low-temperature weak ferroelectricity. The reorientation of these regions in an external electric field could explain the observed electric dispersion. After crossing the morphotropic phase boundary $(\mathrm{x}=0.2)$ the electric properties weaken. This is due to the dominant influence of nonferroelectric LN. Increase of Li ions influences the dielectric losses and a decline of electric properties, whereas the electric conductivity of the materials increase. These leadfree compounds could be of great interest as environmentally - friendly materials in applications as dielectrics for capacitors or actuators.

\section{REFERENCES}

[1] Ch. Chaker, W.E. Charbi, N. Abdelmoula, A. Simon, H. Khemakhen, M. Maglione, Journal of Physic and Chemistry of Solid. 72, 1140-1146 (2011).

[2] B. Lewis, E.A.D White, J. Electronics. 1, 646-664 (1956). 
[3] W. Zapart, M. B. Zapart, P. Czaja, A. Barasiński, Phase Transitions. 79, (6-7), 557-568 (2006)

[4] W. Zapart, M.B. Zapart, P. Czaja, Phase Transitions. 81, (11-12), 1141-1150 (2008)

[5] M.H. Francombe, B. Lewis, J. Electronics. 2, 387-403 (1957).

[6] A.M. Glazer, K. Ishida, Ferroelectrics. 6, 219-224 (1974).

[7] V.A. Isupov, Izv. Nauk SSSR, Seria Fiz. 21, 402-410 (1957).

[8] P.B. Dunbar, J. Mater. Res. 5, 1933-1939 (1990).

[9] W. Śmiga, B. Garbarz-Glos, Cz. Kuś, J. Suchanicz, M. Burzyńska, Ferroelectrics. 292, 145-150 (2003).

[10] L. Pardo, P. Duran-Martin, I.P. Mercurio, L. Nibou, B. Jimenez, J. Phys. Chem. Solids. 58, 1335-1359 (1997).

[11] W. Śmiga, K. Konieczny, Cz. Kuś, M. Burzyńska, Ferroelectrics. 216, 53-57 (1998).

[12] K. Konieczny, Mat. Sci. Eng. B60, 124-127 (1999).

[13] M. Drulis, K. Konieczny, Mat. Sci. Eng. B72, 19-22(2000).

[14] I.P. Raevskii, L.A. Reznichenko, V.G. Smotrakov, V.V. Eremkin, M.A. Malitskaya, E.M. Kuznetsova, L.A. Shilkina, Technical Physics Letters. 26, 744-746 (2000).
[15] I.P. Raevskii, L.A. Reznichenko, V.G. Smotrakov, V.V. Eremkin, M.A. Malitskaya, L.A. Shilkina, E.S. Gagarina, Crystallography Reports. 47, 879-884 (2002).

[16] I.P. Raevskii, et al., Inorg. Mater. 15, 686 (1979).

[17] K. Konieczny, W. Śmiga, Ferroelectrics. 417, (1), 151-160 (2011).

[18] K. Konieczny, W. Śmiga, Integrated Ferroelectrics. 173, 1, 65-70 (2016).

[19] M.H. Francombe, B. Lewis, J. Electronics. 2, 1957 (387-403).

[20] R.M. Henson, R.R. Zeyfang, K.V. Kiehl, J. Am. Ceram. Soc. 60, (1-2), 15-17 (1977).

[21] Y.D. Juang, S.B. Dai, Y.C. Wang, W.Y. Chou, J.S. Hwang, M.L. Hu, W.S. Tse, Solid State Commun. 111, 723-728 (1999).

[22] V.B. Nalbandyan, Journal of Physics and Chemistry of Solids, 65, 1201 (2004).

[23] I.P. Raevskii, M.P. Ivliev, L.A. Reznichenko, M.N. Palatnikov, L.E. Balyunis, M.A. Malitskaya, Technical Physics, 47, 772-776 (2002).

[24] J. Toulouse, X.M. Wang, L.A. Knauss, L.A. Boatner LA, Phys. Rev. B. 43, 8297-8302 (1991). 